Vol. 9 (1): 201-204 (2019)

\title{
A REVIEW OF IRANIAN SCIENTISTS' KNOWLEDGE ON COLD CEREBRAL HUMORS
}

\author{
Atiyeh Dadvar' ${ }^{1}$, Mahdi Yousefi ${ }^{2}$, Seyed Mohammad Bagher Fazljou ${ }^{1}$, Ali Akbar Taheraghdam ${ }^{3 *}$ \\ ${ }^{l}$ Department of Iranian Traditional Medicine, Faculty of Traditional Medicine, \\ Tabriz University of Medical Sciences, Tabriz, Iran; \\ ${ }^{2}$ Department of Iranian Traditional Medicine, Faculty of Traditional Medicine, \\ Mashhsd University of Medical Sciences, Mashhad, Iran; \\ ${ }^{3 *}$ Department of Neurology, Faculty of Medicine, \\ Tabriz University of Medical Sciences, Tabriz, Iran;
}

Corresponding Author Ali Akbar Taheraghdam email: Taheraghdam@yahoo.com;

Received July 2018; Accepted September 2018; Published February 2019;

DOI: https://doi.org/10.31407/ijees9123

UOI license: http://u-o-i.org/1.01/ijees/12608020

\begin{abstract}
In Iranian medicine, brain as one of the most important and vital organs plays a crucial role in the emergence and appearance of its own and other organs' specific functions so that Iranian medical scholars believe that the function of other members is closely linked to the health of the nervous system. The dependence of various parts of natural things on humors indicates their key role in the diagnosis and treatment of diseases. Quantitative and qualitative changes in humors cause material dystemperament in the body and a major part of diseases are caused by material dystemperament. In this article, knowledge of Iranian scientists on cold cerebral humors is investigated.
\end{abstract}

Keywords: Brain, cold humors, Iranian scientists, traditional medicine 